\title{
Prosthesis-patient mismatch after aortic valve replacement predominantly affects patients with preexisting left ventricular dysfunction: Effect on survival, freedom from heart failure, and left ventricular mass regression
}

Marc Ruel, MD, MPH, ${ }^{a, b}$ Hussam Al-Faleh, MD, ${ }^{c}$ Alexander Kulik, MD, ${ }^{a}$ Kwan L. Chan, MD, ${ }^{c}$ Thierry G. Mesana, MD, PhD, and Ian G. Burwash, $\mathrm{MD}^{\mathrm{c}}$

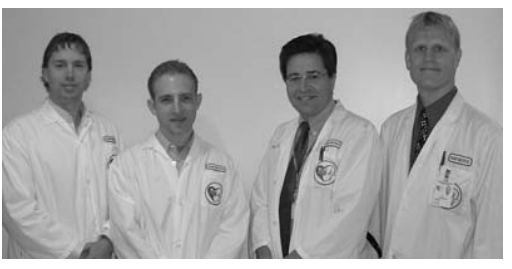

Drs Ruel, Kulik, Mesana, and Burwash (left to right)
Objective: The effect of prosthesis-patient mismatch on clinical outcome and left ventricular mass regression after aortic valve replacement remains controversial. Data on whether the clinical effect of prosthesis-patient mismatch depends on left ventricular function at the time of aortic valve replacement are lacking. This study examined the long-term clinical and echocardiographic effects of prosthesis-patient mismatch in patients with and without left ventricular systolic dysfunction at the time of aortic valve replacement.

Methods: Preoperative and serial postoperative echocardiograms were performed in 805 adults who underwent aortic valve replacement between 1990 and 2003 and who were subsequently followed up in a dedicated valve clinic (follow-up, mean \pm $\mathrm{SD}, 5.5 \pm 3.5$ years; maximum, 14.2 years). Preoperative left ventricular function was defined as normal (ejection fraction $\geq 50 \%$ ) in 548 patients and impaired (ejection fraction $<50 \%$ ) in 257 patients.

Results: Patients with impaired preoperative left ventricular function and prosthesis-patient mismatch (indexed effective orifice area $\leq 0.85 \mathrm{~cm}^{2} / \mathrm{m}^{2}$ ) had a decreased overall late survival (hazard ratio, 2.8; $P=.03$ ), decreased freedom from heart failure symptoms or heart failure death (odds ratio of 5.1 at 3 years after aortic valve replacement; $P=.009$ ), and diminished left ventricular mass regression compared with patients with impaired preoperative left ventricular function and no prosthesispatient mismatch. These effects of prosthesis-patient mismatch were not observed in patients with normal preoperative left ventricular function.

Conclusions: Prosthesis-patient mismatch at an indexed effective orifice area of $0.85 \mathrm{~cm}^{2} / \mathrm{m}^{2}$ or less after aortic valve replacement primarily affects patients with impaired preoperative left ventricular function and results in decreased survival, lower freedom from heart failure, and incomplete left ventricular mass regression. Patients with impaired left ventricular function represent a critical population in whom prosthesis-patient mismatch should be avoided at the time of aortic valve replacement.

A ortic valve replacement (AVR) prolongs life, improves symptoms of heart failure, and induces regression of left ventricular hypertrophy in patients with aortic stenosis or aortic insufficiency for whom an operation is indicated. However, controversy exists as to whether the ability of the replacement prosthesis to allow unimpeded blood flow, a potentially modifiable parameter related to the size and type of prosthesis implanted at operation, influences the long-term outcome of patients undergoing AVR. The term prosthesis-patient mismatch (PPM) has been used to describe the phenomenon in which the effective orifice area (EOA) of the implanted prosthesis may be inadequate for the patient's 


\author{
Abbreviations and Acronyms \\ AVR $=$ aortic valve replacement \\ BSA = body surface area \\ $\mathrm{CI}=$ confidence interval \\ $\mathrm{EOA}=$ effective orifice area \\ $\mathrm{LVEF}=$ left ventricular ejection fraction \\ PPM = prosthesis-patient mismatch
}

body size, potentially resulting in persistent left ventricular outflow tract obstruction. In general, PPM has been defined by a ratio of prosthetic EOA over patient body surface area (BSA), or indexed EOA, of $0.85 \mathrm{~cm}^{2} / \mathrm{m}^{2}$ or less ${ }^{1}$ and has been observed in $19 \%$ to $70 \%$ of patients undergoing AVR. ${ }^{2,3}$ Smaller mismatch thresholds of $0.80 \mathrm{~cm}^{2} / \mathrm{m}^{2}$ or less, $0.75 \mathrm{~cm}^{2} / \mathrm{m}^{2}$ or less, and $0.65 \mathrm{~cm}^{2} / \mathrm{m}^{2}$ or less have been proposed by some investigators. ${ }^{2,3}$

The effect of PPM on survival and left ventricular remodeling after AVR has been controversial. Although some investigators have suggested that PPM results in decreased early and late survival after AVR, ${ }^{3,4}$ others have failed to confirm these findings. ${ }^{2,5-8}$ However, surgical selection factors confound this issue, because patients with PPM are usually older, are more often female, are more often overweight, and have a higher prevalence of comorbidities than those without PPM. ${ }^{2,6}$ Two studies have examined the effect of PPM on freedom from heart failure after AVR, and both have suggested a detrimental effect of PPM. ${ }^{2,9}$ There has been conflicting evidence on the effect of PPM on left ventricular hypertrophy regression. Some investigators have suggested that a small prosthesis does not impede left ventricular remodeling, ${ }^{10-12}$ whereas others have observed decreased regression of left ventricular masses. ${ }^{13-15}$

The relief of aortic obstruction constitutes the main mechanism of clinical improvement and left ventricular mass regression after AVR, and previous data have shown that preexisting left ventricular dysfunction impairs left ventricular mass regression after AVR. ${ }^{16}$ It is therefore conceivable that PPM may affect clinical outcome and left ventricular mass regression in patients with abnormal left ventricular function differently than in those with normal left ventricular function. A recent article suggested that the early perioperative effect of PPM is especially significant in patients with preoperative left ventricular dysfunction. ${ }^{3}$ To date, however, no study has examined the effect of preoperative left ventricular function on the medium- and longterm outcome of patients with PPM after AVR. Thus, the purpose of this study was to investigate whether the effect of PPM on medium- and long-term survival, freedom from heart failure, and left ventricular mass regression is affected by preoperative left ventricular function in patients undergoing AVR.

\section{Methods}

\section{Patient Population and Clinical Follow-up}

The patient population consisted of all adult patients $(n=805)$ who underwent AVR at the University of Ottawa Heart Institute between 1990 and 2003 with a prosthesis that is still commercially available in North America, who survived the operation, and who were followed up annually in a dedicated valve clinic. Patients who underwent concomitant mitral valve repair or replacement were excluded. At each clinic visit, patients had a history focused on the determination of functional status and the occurrence of valve-related complications, physical examination, electrocardiogram, chest radiograph, complete blood count, serum chemistries, and international normalized ratio determinations (when applicable). The total follow-up was 3285 patient-years, with a mean ( $\pm \mathrm{SD}$ ) duration of $5.5 \pm 3.5$ years (range, 60 days to 14.2 years). All patients were followed up for at least 1 outpatient visit.

Patients received anticoagulation treatment according to guidelines in effect at the time, as previously described. ${ }^{17}$ Persistence or recurrence of heart failure after AVR was defined as the composite end point of (1) New York Heart Association functional class III or IV symptoms for more than 4 consecutive weeks or (2) death for which the primary or contributing diagnosis was congestive heart failure. ${ }^{2,3}$ Clinical impressions were corroborated with physical examination, chest radiograph, electrocardiogram, and echocardiographic findings. Persistent postoperative hypertension was defined as a systemic blood pressure greater than $140 / 90 \mathrm{~mm} \mathrm{Hg}$ for 2 or more follow-up visits. Prosthesis-related complications were recorded according to the "Guidelines for Reporting Morbidity and Mortality after Cardiac Valvular Operations." 18

\section{Prostheses}

Prosthesis type and size were recorded for all patients. Prostheses were implanted and oriented according to the manufacturer's instructions. The prostheses used were the Medtronic Hancock II (Medtronic, Inc, Minneapolis, Minn) in 223 patients (28\%), St Jude Medical Standard (St Jude Medical, Inc, St Paul, Minn) in 151 patients (19\%), Carbomedics (Sulzer CarboMedics, Inc, Austin, Tex) in 137 patients (17\%), Medtronic Hall in 89 patients (11\%), homograft in 58 patients (7\%), Medtronic Hancock I in 47 patients (6\%), St Jude Medical HP in 45 patients (6\%), Edwards PERIMOUNT (Edwards Lifesciences, Irvine, Calif) in 38 patients (5\%), MCRI On-X (Medical Carbon Research Institute, Austin, Tex) in 8 patients $(1 \%)$, stentless porcine in 5 patients $(0.6 \%)$, and Carpentier-Edwards Standard in 4 patients $(0.5 \%)$.

The in vivo EOA for each prosthesis type and size was obtained from the literature from patients with normally functioning prostheses ${ }^{1}$ and averaged if more than 1 published value was available. This was supplemented with data provided by the valve manufacturer if published data were insufficient with respect to a specific prosthesis size.

The indexed EOA was obtained by dividing the in vivo EOA by the patient's BSA at the time of operation and was available for all patients. PPM was defined as an indexed EOA of $0.85 \mathrm{~cm}^{2} / \mathrm{m}^{2}$ or less for the purpose of examining clinical and echocardiographic outcomes. In addition, echocardiographic outcomes were examined at mismatch thresholds of $0.80 \mathrm{~cm}^{2} / \mathrm{m}^{2}$ or less and 0.75 $\mathrm{cm}^{2} / \mathrm{m}^{2}$ or less. 
TABLE 1. Patient characteristics

\begin{tabular}{|c|c|c|c|c|}
\hline \multirow[b]{2}{*}{ Variable } & \multicolumn{2}{|c|}{ Normal left ventricular function } & \multicolumn{2}{|c|}{ Impaired left ventricular function } \\
\hline & $\begin{array}{l}\text { No mismatch } \\
(\mathrm{n}=315)\end{array}$ & $\begin{array}{l}\text { Mismatch } \\
(\mathrm{n}=233)\end{array}$ & $\begin{array}{c}\text { No mismatch } \\
(\mathrm{n}=165)\end{array}$ & $\begin{array}{c}\text { Mismatch } \\
(\mathrm{n}=92)\end{array}$ \\
\hline Female sex & $96(30.5 \%)$ & $\begin{array}{c}113(48.5 \%) \\
P<.001\end{array}$ & $36(21.8 \%)$ & $\begin{array}{c}25(27.2 \%) \\
P=.3\end{array}$ \\
\hline Age at operation (y) & $58.5 \pm 14.0$ & $\begin{array}{c}70.8 \pm 10.2 \\
P<.001\end{array}$ & $60.2 \pm 12.9$ & $\begin{array}{c}71.5 \pm 11.5 \\
P=.001\end{array}$ \\
\hline Body surface area $\left(\mathrm{m}^{2}\right)$ & $1.81 \pm 0.24$ & $\begin{array}{c}1.94 \pm 0.22 \\
P<.001\end{array}$ & $1.81 \pm 0.22$ & $\begin{array}{c}1.95 \pm 0.22 \\
P<.001\end{array}$ \\
\hline \multicolumn{5}{|l|}{ NYHA class } \\
\hline I & $90(28.6 \%)$ & $57(24.5 \%)$ & $27(16.4 \%)$ & $21(22.8 \%)$ \\
\hline II & $103(32.7 \%)$ & $60(25.8 \%)$ & $40(24.2 \%)$ & $17(18.5 \%)$ \\
\hline III & $81(25.7 \%)$ & $81(34.8 \%)$ & $61(37.0 \%)$ & $39(42.4 \%)$ \\
\hline IV & $41(13.0 \%)$ & $\begin{array}{l}35(15.0 \%) \\
P=.1\end{array}$ & $37(22.4 \%)$ & $\begin{array}{c}15(16.3 \%) \\
P=.3\end{array}$ \\
\hline \multicolumn{5}{|l|}{ Left ventricular grade* } \\
\hline 1 & $315(100 \%)$ & $233(100 \%)$ & 0 & 0 \\
\hline 2 & 0 & 0 & $82(49.7 \%)$ & $43(46.7 \%)$ \\
\hline 3 & 0 & 0 & $51(30.9 \%)$ & $31(33.7 \%)$ \\
\hline 4 & 0 & $\begin{array}{c}0 \\
P=\mathrm{NA}\end{array}$ & $32(19.4 \%)$ & $\begin{array}{c}18(19.6 \%) \\
P=.9\end{array}$ \\
\hline End-diastolic diameter (cm) & $5.1 \pm 0.6$ & $\begin{array}{l}5.0 \pm 0.6 \\
P=.1\end{array}$ & $6.0 \pm 0.8$ & $\begin{array}{l}5.9 \pm 0.9 \\
P=.3\end{array}$ \\
\hline End-systolic diameter (cm) & $3.0 \pm 0.6$ & $\begin{array}{l}2.9 \pm 0.6 \\
P=.4\end{array}$ & $4.5 \pm 1.0$ & $\begin{array}{l}4.4 \pm 0.9 \\
P=.5\end{array}$ \\
\hline Coronary artery disease & $80(25.4 \%)$ & $\begin{array}{l}87(37.3 \%) \\
P=.003\end{array}$ & $56(33.9 \%)$ & $\begin{array}{c}45(48.9 \%) \\
P=.02\end{array}$ \\
\hline Atrial fibrillation & $30(9.5 \%)$ & $\begin{array}{l}32(13.7 \%) \\
P=.1\end{array}$ & $23(13.9 \%)$ & $\begin{array}{c}17(18.5 \%) \\
P=.3\end{array}$ \\
\hline Previous aortic valve replacement & $63(20.0 \%)$ & $\begin{array}{l}33(14.2 \%) \\
P=.1\end{array}$ & $28(17.0 \%)$ & $\begin{array}{c}10(10.9 \%) \\
P=.2\end{array}$ \\
\hline Operative indication for aortic stenosis & $234(74.3 \%)$ & $\begin{array}{c}201(86.3 \%) \\
P=.001\end{array}$ & $101(61.2 \%)$ & $\begin{array}{c}79(85.9 \%) \\
P<.001\end{array}$ \\
\hline Mean preoperative AVA $\left(\mathrm{cm}^{2}\right)$ & $0.74 \pm 0.19$ & $\begin{array}{c}0.75 \pm 0.73 \\
P=.8\end{array}$ & $0.73 \pm 0.24$ & $\begin{array}{c}0.70 \pm 0.21 \\
P=.3\end{array}$ \\
\hline Bioprosthetic valve implant & $76(24.1 \%)$ & $\begin{array}{c}183(78.5 \%) \\
P<.001\end{array}$ & $33(20.0 \%)$ & $\begin{array}{c}79(85.9 \%) \\
P<.001\end{array}$ \\
\hline Aortic annulus or root enlargement $\dagger$ & $33(10.5 \%)$ & $\begin{array}{l}25(10.7 \%) \\
P=.9\end{array}$ & $13(7.9 \%)$ & $\begin{array}{l}7(7.6 \%) \\
P=.9\end{array}$ \\
\hline
\end{tabular}

Mismatch stands for prosthesis-patient mismatch, defined as a ratio of the prosthesis's effective orifice area over the patient's body surface area equal to or less than $0.85 \mathrm{~cm}^{2} / \mathrm{m}^{2}$. P values refer to the comparison between mismatch and no-mismatch patients within the normal and impaired left ventricular function groups. Data are mean \pm SD or $\mathrm{n}(\%)$. NYHA, New York Heart Association; NA, not applicable; AVA, aortic valve area. *Grade 1, left ventricular ejection fraction of $50 \%$ or more; grade 2, ejection fraction of $40 \%$ to $49 \%$; grade 3, ejection fraction of $30 \%$ to $39 \%$; grade 4 , ejection fraction of less than $30 \%$. †Consists of annular (Nicks, Manouguian, Konno) or aortic root enlargement using pericardium or Dacron.

\section{Echocardiography Follow-up}

Patients underwent a complete M-mode, 2-dimensional, and Doppler transthoracic echocardiogram before AVR and underwent serial echocardiographic examinations on a biannual basis or as clinically indicated after AVR. Left ventricular end-diastolic and endsystolic diameters, septum and posterior wall thicknesses, and left atrial anteroposterior diameters were measured from the M-mode recordings according to the recommendations of the American Society of Echocardiography. ${ }^{19}$ Left ventricular mass was calculated by using the modified formula of the American Society of
Echocardiography. ${ }^{20}$ Left ventricular ejection fraction (LVEF) was quantified by visual estimation by 1 or more of 4 blinded observers. ${ }^{21}$ Left ventricular systolic function was graded as 1 , normal (LVEF $\geq 50 \%$ ); 2, mildly impaired (LVEF 40\%-49\%); 3, moderately impaired (LVEF 30\%-39\%); or 4, severely impaired (LVEF $<30 \%$ ). To assess the effect of preoperative left ventricular function on the effect of PPM, patients were divided into those with normal ( $\mathrm{LVEF} \geq 50 \%$ ) and impaired (LVEF $<50 \%$ ) left ventricular systolic function. Peak instantaneous and mean transvalvular and transprosthesis pressure gradients were derived by modified 
A

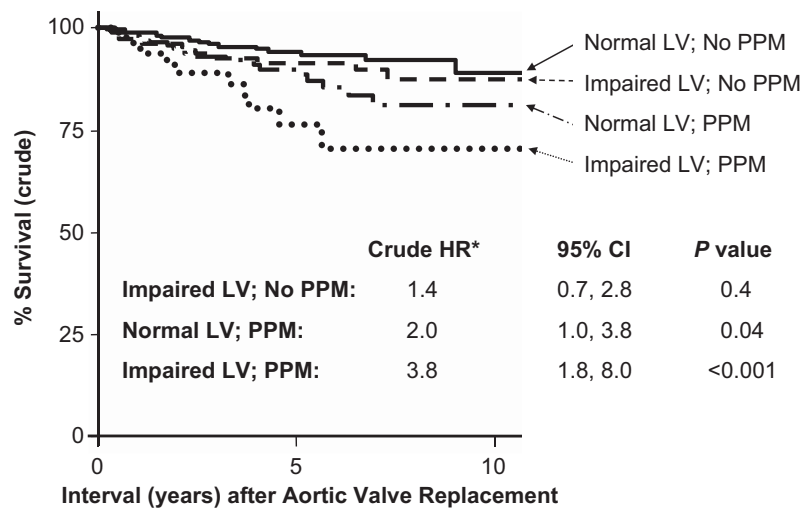

B

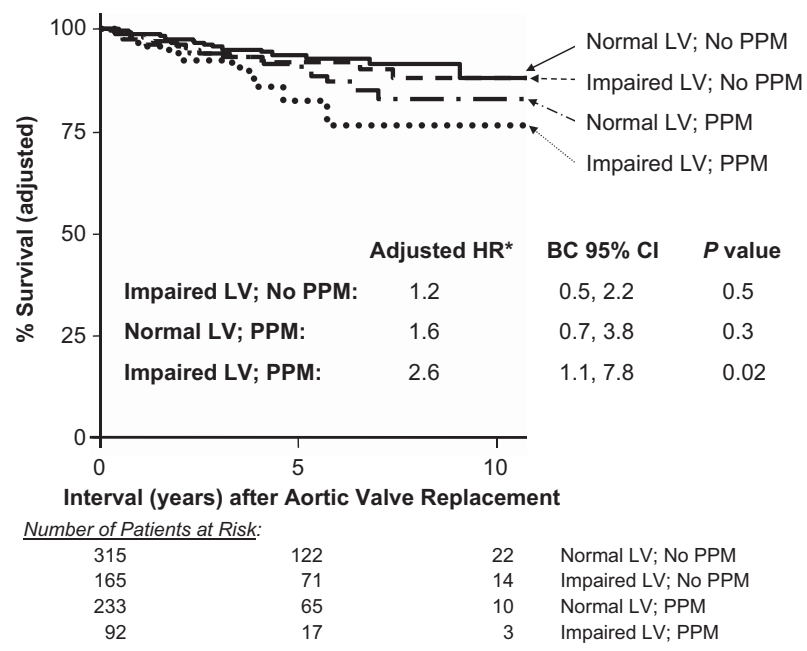

Figure 1. Crude (A) and adjusted (B) survival after aortic valve replacement, by left ventricular function and prosthesis-patient mismatch. Patients with the combination of impaired preoperative left ventricular function and postoperative prosthesis-patient mismatch had lower survival after aortic valve replacement, despite adjustment for age, other risk factors for mortality after $\mathrm{AVR}^{2}{ }^{2}$ and baseline patient characteristics. ${ }^{*}$ Crude and adjusted hazard ratios are in comparison to the "Normal LV; No PPM" group. $C l$, Confidence interval; $H R$, hazard ratio; $L V$, left ventricle; PPM, prosthesis-patient mismatch.

Bernoulli equations, and the preoperative aortic valve EOA was calculated with the continuity equation. ${ }^{22}$

\section{Statistical Analyses}

Data were imported and analyzed in Intercooled Stata 8 (Stata Corp, College Station, Tex). Continuous data are presented as mean $\pm \mathrm{SD}$ or mean (lower $95 \%$ confidence limit, upper $95 \%$ confidence limit).

Survival. Potential predictors of survival, including left ventricular function and PPM indicators, were tested for equality with
Heart failure symptoms or death from heart failure by 3 years after aortic valve replacement

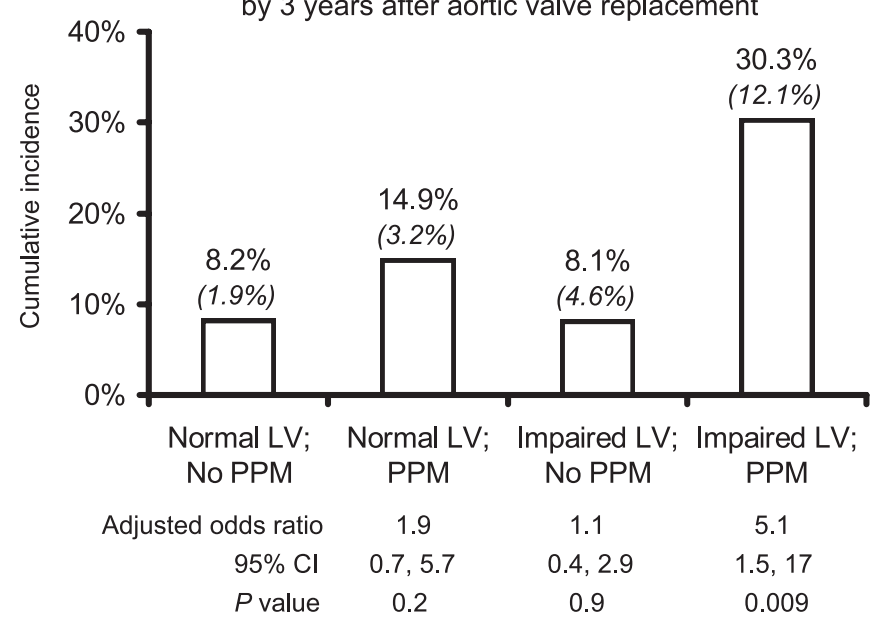

Figure 2. Effect of preoperative left ventricular function and prosthesis-patient mismatch on the cumulative incidence of heart failure symptoms or death related to heart failure at 3 years after aortic valve replacement. Nonitalic percentages, bars, and odds ratios refer to the occurrence of either heart failure symptoms or death. Italic percentages in parentheses indicate heart failure death. Odds ratios are in comparison to the "Normal LV; No PPM" group and are adjusted for risk factors of decreased freedom from heart failure after $\mathbf{A V R}^{2}$ and for baseline patient characteristics. Patients with the combination of impaired preoperative left ventricular function and postoperative prosthesis-patient mismatch had a lower freedom from heart failure despite adjustment for confounding factors. $C l$, Confidence interval; $L V$, left ventricle; PPM, prosthesis-patient mismatch.

a log-rank test. For multivariate models, the proportional hazard assumption was tested with generalized Cox-Snell residuals. If the assumption was met, Cox proportional hazards models were developed (1) by incorporating variables that had a $P$ value of .05 or less on log-rank testing; (2) by forcing into models the risk factors for decreased survival after AVR identified previously ${ }^{2}$ (ie, age, atrial fibrillation, preoperative heart failure functional class, coronary artery disease, smoking, and insulin-dependent diabetes mellitus); and (3) by incorporating into the model patient characteristics that differed between the mismatch and no-mismatch groups. To account for confounding, no automated model selection procedure was used, and all covariates were used simultaneously. Proportional hazards models were subjected to 100 bootstrap replications, as previously described, ${ }^{2}$ and estimates of standard error, bias, and $95 \%$ confidence intervals (CIs) were derived from the 100 replications by using a bias-corrected method.

Heart failure. The effects of left ventricular dysfunction and PPM on the cumulative incidence of heart failure symptoms or heart failure-related death within 3 years after AVR were examined by logistic regression. A 3-year period was arbitrarily chosen to allow maximal symptom improvement and left ventricular remodeling in the greatest potential number of cohort patients ${ }^{2,23}$ while minimizing the possible confounding effects of early struc- 
TABLE 2. Postoperative left ventricular mass regression at increasing degrees of prosthesis-patient mismatch, according

\begin{tabular}{|c|c|c|c|c|}
\hline \multirow[b]{2}{*}{ Variable } & \multicolumn{4}{|c|}{ Normal left ventricular function } \\
\hline & No mismatch & $\begin{array}{l}\text { Mismatch } \\
\leq 0.85 \mathrm{~cm}^{2} / \mathrm{m}^{2}\end{array}$ & $\begin{array}{l}\text { Mismatch } \\
\leq 0.80 \mathrm{~cm}^{2} / \mathrm{m}^{2}\end{array}$ & $\begin{array}{l}\text { Mismatch } \\
\leq 0.75 \mathrm{~cm}^{2} / \mathrm{m}^{2}\end{array}$ \\
\hline Change in LV mass $(\mathrm{g})^{*}$ & $-60(-69,-50)$ & $\begin{array}{c}-57(-67,-47) \\
P=.7\end{array}$ & $\begin{array}{c}-57(-67,-46) \\
P=.7\end{array}$ & $\begin{array}{c}-68(-80,-55) \\
P=.1\end{array}$ \\
\hline $\begin{array}{l}\text { Relative change in LV mass ( } \% \text { of } \\
\text { preoperative LV mass) }\end{array}$ & $-20 \%(-24,-17)$ & $\begin{array}{c}-22 \%(-26,-19) \\
P=.3\end{array}$ & $\begin{array}{c}-24 \%(-28,-20) \\
P=.2\end{array}$ & $\begin{array}{c}-27 \%(-32,-23) \\
P=.1\end{array}$ \\
\hline Indexed change in LV mass $\left(\mathrm{g} / \mathrm{m}^{2}\right.$ of $\left.B S A\right)$ & $-33(-39,-28)$ & $\begin{array}{c}-29(-34,-24) \\
P=.3\end{array}$ & $\begin{array}{c}-28(-33,-23) \\
P=.3\end{array}$ & $\begin{array}{c}-34(-40,-27) \\
P=.5\end{array}$ \\
\hline $\begin{array}{l}\text { Indexed change in LV mass regression } \\
\text { coefficient }\left(\mathrm{g} / \mathrm{m}^{2} \text { of BSA } \dagger\right.\end{array}$ & NA & $\begin{array}{l}1(-9,7) \\
P=.8\end{array}$ & $\begin{array}{c}0.4(-8,9) \\
P=.9\end{array}$ & $\begin{array}{l}8(-17,1) \\
P=.1\end{array}$ \\
\hline
\end{tabular}

Mismatch threshold values represent the prosthesis's effective orifice area divided by the patient's body surface area. Data are expressed as mean (lower $95 \%$ confidence limit, upper $95 \%$ confidence limit). $P$ values refer to the comparison between prosthesis-patient mismatch (at the specified degree) and no-mismatch patients. $L V$, Left ventricular; $B S A$, body surface area; $N A$, not applicable. *Calculated as the lowest postoperative echocardiographically derived left ventricular mass minus the preoperative left ventricular mass. $†$ Multivariate linear regression models include as simultaneous covariates age, sex, postoperative hypertension, and prosthesis-patient mismatch at the specified degree.

tural valve deterioration on heart failure symptoms. ${ }^{24}$ Logistic regression models incorporated (1) the risk factors for decreased freedom from heart failure after AVR identified previously ${ }^{2}$ (ie, age, atrial fibrillation, coronary disease, and redo AVR status), and (2) patient characteristics that differed between the PPM and no-PPM groups.

Left ventricular mass regression. Echocardiographic left ventricular mass changes were derived from the lowest postoperative echocardiographically derived left ventricular mass minus the preoperative left ventricular mass. These changes were expressed in absolute fashion in relation to the preoperative left ventricular mass and indexed to the patient's baseline BSA. Changes were compared between PPM and no-PPM patients within the 2 subgroups of normal and impaired preoperative left ventricular function by using an analysis of variance. Bonferroni corrections for multiple tests were applied as appropriate. In addition, the independent effect of PPM on left ventricular mass regression within a left ventricular function subgroup was examined by using linear regression models that also incorporated age, sex, and postoperative hypertension as potential confounders of altered left ventricular mass regression. ${ }^{25,26}$

\section{Results}

\section{Patient Characteristics}

The preoperative characteristics of the cohort are shown in Table 1. Patients with PPM defined as an indexed EOA of $0.85 \mathrm{~cm}^{2} / \mathrm{m}^{2}$ or less were significantly older, were more often female, had a larger BSA, had a higher coprevalence of coronary artery disease, were more often operated on for aortic stenosis, and more often received a bioprosthesis than patients without PPM. Consequently, these variables were forced into the multivariate regression models that estimated survival, heart failure, and left ventricular mass in addition to the other a priori covariates described in the "Statistical Analyses" section.

\section{Native Aortic Valve and Prosthetic Valve Hemodynamics}

Before surgery, the peak and mean instantaneous transvalvular pressure gradients were similar in patients with PPM compared with those without PPM (peak, $76.4 \pm$ $30.3 \mathrm{~mm} \mathrm{Hg}$ vs $72.4 \pm 34.6 \mathrm{~mm} \mathrm{Hg}$; mean, $45.3 \pm 18.9$ $\mathrm{mm} \mathrm{Hg}$ vs $42.5 \pm 21.8 \mathrm{~mm} \mathrm{Hg}$, respectively; $P>$.1). Significantly higher preoperative peak and mean instantaneous transvalvular pressure gradients were observed in patients with normal compared with impaired preoperative left ventricular function (peak, $77.2 \pm 33.6 \mathrm{~mm} \mathrm{Hg}$ vs $67.2 \pm 30.3$ $\mathrm{mm} \mathrm{Hg}$; mean, $45.4 \pm 21.2 \mathrm{~mm} \mathrm{Hg}$ vs $40.0 \pm 18.9 \mathrm{~mm} \mathrm{Hg}$, respectively; $P<.002$ ). Preoperative aortic valve EOA was similar in patients with normal and impaired left ventricular function $\left(0.76 \pm 0.63 \mathrm{~cm}^{2}\right.$ vs $\left.0.72 \pm 0.25 \mathrm{~cm}^{2} ; P=.4\right)$.

After surgery, patients with PPM had higher peak and mean instantaneous transprosthesis gradients compared with patients with no PPM (peak, $32.3 \pm 16.3 \mathrm{~mm} \mathrm{Hg}$ vs $27.3 \pm$ $13.6 \mathrm{~mm} \mathrm{Hg}$; mean, $17.8 \pm 9.5 \mathrm{~mm} \mathrm{Hg}$ vs $14.7 \pm 7.6$ $\mathrm{mm} \mathrm{Hg}$, respectively; $P<.001$ ). There was no significant difference in postoperative peak and mean instantaneous transprosthesis gradients between patients with normal and impaired preoperative left ventricular function (peak, $29.8 \pm 15.1 \mathrm{~mm} \mathrm{Hg}$ vs $27.8 \pm 14.4 \mathrm{~mm} \mathrm{Hg}$; mean, $16.1 \pm$ $8.4 \mathrm{~mm} \mathrm{Hg}$ vs $15.4 \pm 8.8 \mathrm{~mm} \mathrm{Hg}$, respectively; $P>.1$ ).

\section{Survival}

Figure 1 displays the crude and adjusted survival of the total cohort according to the preoperative left ventricular function and the presence of PPM after AVR. Patients with the combination of impaired preoperative left ventricular function and postoperative PPM had decreased survival after AVR, both crude (Figure 1, $A$ ) and after adjustment for age, sex, atrial fibrillation, preoperative heart failure functional 
to preoperative left ventricular function

\begin{tabular}{|c|c|c|c|}
\hline \multicolumn{4}{|c|}{ Impaired left ventricular function } \\
\hline No mismatch & $\begin{array}{c}\text { Mismatch } \\
\leq 0.85 \mathrm{~cm}^{2} / \mathrm{m}^{2}\end{array}$ & $\begin{array}{c}\text { Mismatch } \\
\leq 0.80 \mathrm{~cm}^{2} / \mathrm{m}^{2}\end{array}$ & $\begin{array}{c}\text { Mismatch } \\
\leq 0.75 \mathrm{~cm}^{2} / \mathrm{m}^{2}\end{array}$ \\
\hline$-93(-112,-75)$ & $\begin{array}{c}-57(-75,-39) \\
P=.01\end{array}$ & $\begin{array}{c}-47(-69,-27) \\
P=.005\end{array}$ & $\begin{array}{c}-36(-57,-16) \\
P=.002\end{array}$ \\
\hline$-25 \%(-30,-21)$ & $\begin{array}{c}-16 \%(-22,-11) \\
P=.03\end{array}$ & $\begin{array}{c}-14 \%(-21,-8) \\
P=.009\end{array}$ & $\begin{array}{c}-12 \%(-20,-4) \\
P=.008\end{array}$ \\
\hline$-52(-63,-41)$ & $\begin{array}{c}-30(-40,-20) \\
P=.01\end{array}$ & $\begin{array}{c}-25(-36,-14) \\
P=.004\end{array}$ & $\begin{array}{c}-18(-29,-8) \\
P=.002\end{array}$ \\
\hline NA & $\begin{array}{c}-17(0,-34) \\
P=.05\end{array}$ & $\begin{array}{c}-21(-1,-40) \\
P=.03\end{array}$ & $\begin{array}{c}-26(-4,-47) \\
P=.02\end{array}$ \\
\hline
\end{tabular}

class, coronary artery disease, smoking, insulin-dependent diabetes mellitus, predominant valve lesion at operation, and use of a bioprosthesis (Figure 1,B). An independent death hazard ratio of 2.6 (bias-corrected 95\% CI, 1.1-7.8; $P=.02$ ) was observed in patients with impaired left ventricular function and PPM compared with patients with normal left ventricular function and no PPM. Furthermore, a death hazard ratio of 2.8 (95\% CI, 1.1-8.0; $P=.03)$ was observed in patients with impaired left ventricular function and PPM compared with patients with impaired left ventricular function and no PPM. In contrast, there was no difference in crude or adjusted survival between patients with normal preoperative left ventricular function and PPM versus patients with normal preoperative left ventricular function and no PPM (hazard ratio, 1.6; 95\% CI, 0.7-3.8; $P=.3)$.

\section{Heart Failure}

The combination of impaired preoperative left ventricular function and postoperative PPM had a negative effect on freedom from heart failure at 3 years after AVR (Figure 2). This was seen both on univariate analyses and after adjustment for age, sex, atrial fibrillation, coronary disease, predominant valve lesion at operation, use of a bioprosthesis, and redo AVR. The adjusted odds ratio for heart failure at 3 years after AVR in patients with the combination of impaired preoperative left ventricular function and postoperative PPM was 5.1 (95\% CI, 1.5-17; $P=.009)$. In no other subgroup defined by preoperative left ventricular function or PPM was a significant increase in the cumulative incidence of heart failure observed.

\section{Left Ventricular Mass Regression}

Patients with impaired left ventricular systolic function and PPM demonstrated less left ventricular mass regression compared with patients with impaired left ventricular systolic function without PPM (Table 2). This detrimental effect was greater as PPM became more severe and was observed for the absolute change in left ventricular mass, the relative change in left ventricular mass as a percentage of preoperative left ventricular mass, and the change in left ventricular mass indexed for BSA. The multivariate regression coefficient for the change in left ventricular mass indexed for BSA, adjusted for patient characteristics and the presence of persistent hypertension during postoperative follow-up, was also significantly reduced in patients with impaired left ventricular systolic function and PPM and independently demonstrated less mass regression as the severity of PPM increased. In contrast, left ventricular mass regression, as assessed by the absolute change in left ventricular mass, the relative change in left ventricular mass as a percentage of preoperative left ventricular mass, or the change in left ventricular mass indexed for BSA, was not significantly different between PPM and non-PPM patients with normal preoperative left ventricular systolic function.

\section{Discussion}

The concept of PPM was first introduced by Rahimtoola ${ }^{27}$ in 1978 as a condition in which the in vivo EOA of the aortic prosthetic valve is less than that of the native human valve. Subsequent work from numerous groups over the years has yielded contradictory results with respect to the effect of PPM on late survival, clinical outcome, and left ventricular mass regression after AVR. ${ }^{2-14}$ The main finding of this study is that PPM primarily affects patients with impaired left ventricular function at the time of AVR. Independent detrimental effects of PPM were observed only in patients with impaired preoperative left ventricular systolic function, in whom PPM was associated with decreased 
overall long-term survival, lower freedom from heart failure, and diminished left ventricular mass regression. Patients with PPM and impaired left ventricular systolic function at the time of AVR have a greater than twofold increase in the risk of late death, a fivefold increase in the cumulative incidence of heart failure by 3 years, and approximately $40 \%$ less left ventricular mass regression compared with patients with left ventricular dysfunction and no PPM. Furthermore, the amount of left ventricular mass regression decreases with increasing severity of PPM in patients with impaired preoperative left ventricular function. Thus, in patients with left ventricular dysfunction at the time of AVR, there seems to be a minimal threshold in prosthesis size, near an indexed EOA of $0.85 \mathrm{~cm}^{2} / \mathrm{m}^{2}$, beyond which survival and cardiac recovery may not reach their maximum potential after valve replacement. PPM at or beyond this threshold should therefore be avoided in patients with preexisting left ventricular dysfunction.

Conversely, our data also demonstrate that PPM at a threshold of $0.85 \mathrm{~cm}^{2} / \mathrm{m}^{2}$ or less does not result in significant detrimental effects on overall long-term survival, freedom from heart failure, and left ventricular mass regression in patients with normal preoperative left ventricular function. Thus, special techniques other than optimized prosthesis selection based on hemodynamics that are used to avoid mismatch and that may occasionally be associated with additional operative risk, such as the use of aortic root enlargement or the implantation of a stentless valve, do not seem justified solely on the basis of potential improvement in late outcome in patients with normal left ventricular function and a predicted indexed EOA of less than 0.85 $\mathrm{cm}^{2} / \mathrm{m}^{2}$ at the time of AVR. However, because this study examined only common mismatch thresholds and did not evaluate very severe mismatch, such as $0.65 \mathrm{~cm}^{2} / \mathrm{m}^{2}$ or less (a value occasionally chosen by other investigators), ${ }^{3}$ we cannot comment on whether more severe PPM might in turn lead to a significant late clinical or echocardiographic effect in patients with normal left ventricular function.

Recently, Blais and colleagues ${ }^{3}$ suggested that the early perioperative clinical effect of PPM may be most significant in patients with preoperative left ventricular dysfunction. These investigators observed a 3.7 -fold increase in the 30-day mortality rate in patients with PPM and a left ventricular ejection fraction of less than $40 \%$ compared with patients with PPM and an ejection fraction greater than $40 \%$. Patients with PPM and a preoperative left ventricular ejection fraction less than $40 \%$ had a 77.1 relative risk ratio for mortality at 30 days compared with an 11.3 relative risk ratio for patients with PPM and a left ventricular ejection fraction of $40 \%$ or more. To our knowledge, no study to date has evaluated the medium- and long-term effect of PPM after AVR on the basis of the preoperative left ventricular function and separately analyzed patients with nor- mal versus impaired left ventricular function. Our data expand on the observations of Blais and colleagues and demonstrate that PPM at a threshold of $0.85 \mathrm{~cm}^{2} / \mathrm{m}^{2}$ or less decreases long-term survival and freedom from heart failure and impairs left ventricular mass regression beyond the perioperative period in patients with impaired preoperative left ventricular function, but not in patients with normal preoperative left ventricular function. It is possible that the interaction between PPM and preoperative left ventricular function identified in this study may have accounted in part for the often-conflicting observations on the effect of PPM in previous studies.

This study examined the outcome of patients who survived AVR and did not focus on early perioperative outcomes, in order to evaluate left ventricular mass regression and heart failure symptoms, which cannot be adequately evaluated in the perioperative period. Furthermore, surgical decision making and confounding by indication may especially bias perioperative outcomes in patients with PPM, because surgeons may tend to avoid the more complex operation required to implant a larger prosthesis and avoid mismatch in patients with poor physical condition and significant comorbidity who are at higher baseline operative risk, thus resulting in an apparent increase in perioperative mortality in patients receiving a smaller prosthesis. This potential perioperative bias may therefore have been minimized by our study design.

\section{Limitations}

Our study used the indexed in vivo EOA values derived from normally functioning valves rather than prosthesis size to determine the presence of PPM after AVR. ${ }^{1}$ The use of other indices, such as prosthesis label size, which is not standardized, or geometric internal orifice area, which does not account for the many characteristics of a valve that may contribute significantly to the EOA (such as prosthesis height, profile, opening angle, and leaflet inertia), may have played a role in the discrepancies between studies that have examined the effect of PPM. Using the EOA derived by the Doppler-echo continuity equation in individual patients after prosthesis implantation might have better quantified the degree of PPM; however, this method also has several limitations related to difficulties of accurately measuring the left ventricular outflow diameter caused by reverberations from the prosthetic valve and the presence of large localized transprosthetic gradients and nonflat transprosthetic spatial velocity profiles, which frequently result in large discrepancies between Doppler-echo and actual EOA measurements. ${ }^{28-30}$ Furthermore, the EOA derived from individual patients has a major drawback because it is not available at the time of surgical decision making and therefore cannot help to avoid PPM during the operation. This EOA can be determined only once the prosthesis has been inserted, the 
patient has been weaned from cardiopulmonary bypass, and the preload, afterload, and contractility have normalized. Therefore, the EOA of an individual patient has little or no role in predicting whether PPM will be avoided by using a given prosthesis and size and whether another prosthesis or size should be selected and/or aortic root enlargement be performed before implantation. It is important to note that PPM, as defined in this study by using the in vivo EOA, was strongly predictive of early and late postoperative transprosthesis gradients, thus suggesting that our methodology accurately reflected aortic root hemodynamics in individual patients.

Previous myocardial infarction is difficult to rule out with certainty in patients with severe valvular disease, coronary artery disease, and left ventricular dysfunction. Consequently, it was not always possible to establish the exact underlying etiology of left ventricular dysfunction in affected patients of this cohort, even though the coprevalence of coronary artery disease at baseline was adjusted for in the multivariate analyses. It is possible that the underlying mechanism of left ventricular dysfunction in affected patients may have varied between the mismatch and nomismatch groups in a proportion that was different from that of their respective coprevalence of coronary disease, and, if so, this could have confounded the results. Furthermore, the findings of this study, as with any large observational cohort, may not necessarily be generalizable to all patients with prosthetic valves, because it represents a single institution's experience and may have been affected by referral and patient care patterns.

\section{Conclusions}

The effect of PPM on left ventricular mass regression, freedom from heart failure, and survival in patients after AVR is dependent on preoperative left ventricular function. Patients with PPM and left ventricular systolic dysfunction have a greater than twofold increase in the risk of late death, a fivefold increase in the cumulative incidence of heart failure by 3 years, and incomplete left ventricular mass regression compared with patients with left ventricular dysfunction and no PPM. In contrast, the presence of PPM at a threshold of $0.85 \mathrm{~cm}^{2} / \mathrm{m}^{2}$ or less in patients with normal left ventricular function at the time of AVR was not associated with a significant increase in late adverse events. The results of this study suggest that implantation of an aortic valve prosthesis with an estimated indexed EOA of $0.85 \mathrm{~cm}^{2} / \mathrm{m}^{2}$ or less should be avoided in patients with a preoperative LVEF of less than $50 \%$. Patients with impaired left ventricular function represent a critical population in whom special technical steps or careful prosthesis selection based on hemodynamics should be performed at the time of AVR to avoid postoperative PPM and to potentially improve long-term outcomes.

\section{References}

1. Pibarot P, Dumesnil JG. Hemodynamic and clinical impact of prosthesispatient mismatch in the aortic valve position and its prevention. J Am Coll Cardiol. 2000;36:1131-41.

2. Ruel M, Rubens FD, Masters RG, Pipe AL, Bedard P, Hendry PJ, et al. Late incidence and predictors of persistent or recurrent heart failure in patients with aortic prosthetic valves. J Thorac Cardiovasc Surg. 2004; 127:149-59.

3. Blais C, Dumesnil JG, Baillot R, Simard S, Doyle D, Pibarot P. Impact of valve prosthesis-patient mismatch on short-term mortality after aortic valve replacement. Circulation. 2003;108:983-8.

4. Rao V, Jamieson WR, Ivanov J, Armstrong S, David TE. Prosthesispatient mismatch affects survival after aortic valve replacement. $\mathrm{Cir}$ culation. 2000;102:III5-9.

5. Frapier JM, Rouviere P, Razcka F, Aymard T, Albat B, Chaptal PA. Influence of patient-prosthesis mismatch on long-term results after aortic valve replacement with a stented bioprosthesis. J Heart Valve Dis. 2002;11:543-51.

6. Medalion B, Blackstone EH, Lytle BW, White J, Arnold JH, Cosgrove DM. Aortic valve replacement: is valve size important? J Thorac Cardiovasc Surg. 2000;119:963-74.

7. Hanayama N, Christakis GT, Mallidi HR, Joyner CD, Fremes SE, Morgan CD, et al. Patient prosthesis mismatch is rare after aortic valve replacement: valve size may be irrelevant. Ann Thorac Surg. 2002;73: 1822-9; discussion 1829.

8. Penta de Peppo A, Zeitani J, Nardi P, Iaci G, Polisca P, De Paulis R, et al. Small "functional" size after mechanical aortic valve replacement: no risk in young to middle-age patients. Ann Thorac Surg. 2005;79:1915-20.

9. Pibarot P, Dumesnil JG, Lemieux M, Cartier P, Metras J, Durand LG. Impact of prosthesis-patient mismatch on hemodynamic and symptomatic status, morbidity and mortality after aortic valve replacement with a bioprosthetic heart valve. J Heart Valve Dis. 1998;7:211-8.

10. Bech-Hanssen O, Caidahl K, Wall B, Myken P, Larsson S, Wallentin I. Influence of aortic valve replacement, prosthesis type, and size on functional outcome and ventricular mass in patients with aortic stenosis. J Thorac Cardiovasc Surg. 1999;118:57-65.

11. Knez I, Rienmuller R, Maier R, Rehak P, Schrottner B, Machler H, et al. Left ventricular architecture after valve replacement due to critical aortic stenosis: an approach to dis-/qualify the myth of valve prosthesis-patient mismatch? Eur J Cardiothorac Surg. 2001;19:797-805.

12. Amarelli C, Della Corte A, Romano G, Iasevoli G, Dialetto G, De Santo LS, et al. Left ventricular mass regression after aortic valve replacement with 17-mm St Jude Medical mechanical prostheses in isolated aortic stenosis. J Thorac Cardiovasc Surg. 2005;129:512-7.

13. Fuster RG, Montero Argudo JA, Albarova OG, Sos FH, Lopez SC, Codoner $\mathrm{MB}$, et al. Patient-prosthesis mismatch in aortic valve replacement: really tolerable? Eur J Cardiothorac Surg. 2005;27:441-9; discussion 449.

14. Tasca G, Brunelli F, Cirillo M, Dalla Tomba M, Mhagna Z, Troise G, et al. Impact of the improvement of valve area achieved with aortic valve replacement on the regression of left ventricular hypertrophy in patients with pure aortic stenosis. Ann Thorac Surg. 2005;79:1291-6; discussion 1296.

15. Tasca G, Brunelli F, Cirillo M, DallaTomba M, Mhagna Z, Troise G, et al. Impact of valve prosthesis-patient mismatch on left ventricular mass regression following aortic valve replacement. Ann Thorac Surg. 2005;79:505-10.

16. Lund O, Emmertsen K, Dorup I, Jensen FT, Flo C. Regression of left ventricular hypertrophy during 10 years after valve replacement for aortic stenosis is related to the preoperative risk profile. Eur Heart J. 2003;24:1437-46.

17. Ruel M, Masters RG, Rubens FD, Bedard PJ, Pipe AL, Goldstein WG, et al. Late incidence and determinants of stroke after aortic and mitral valve replacement. Ann Thorac Surg. 2004;78:77-83; discussion 83-4. 
18. Edmunds LH Jr, Clark RE, Cohn LH, Grunkemeier GL, Miller DC, Weisel RD. Guidelines for reporting morbidity and mortality after cardiac valvular operations. Ad Hoc Liaison Committee for Standardizing Definitions of Prosthetic Heart Valve Morbidity of The American Association for Thoracic Surgery and The Society of Thoracic Surgeons. J Thorac Cardiovasc Surg. 1996;112:708-11.

19. Sahn DJ, DeMaria A, Kisslo J, Weyman A. Recommendations regarding quantitation in M-mode echocardiography: results of a survey of echocardiographic measurements. Circulation. 1978;58:1072-83.

20. Devereux RB, Alonso DR, Lutas EM, Gottlieb GJ, Campo E, Sachs I, et al. Echocardiographic assessment of left ventricular hypertrophy: comparison to necropsy findings. Am J Cardiol. 1986;57:450-8.

21. McGowan JH, Cleland JG. Reliability of reporting left ventricular systolic function by echocardiography: a systematic review of 3 methods. Am Heart J. 2003;146:388-97.

22. Burwash IG, Thomas DD, Sadahiro M, Pearlman AS, Verrier ED, Thomas R, et al. Dependence of Gorlin formula and continuity equation valve areas on transvalvular volume flow rate in valvular aortic stenosis. Circulation. 1994;89:827-35.

23. Krayenbuehl HP, Hess OM, Monrad ES, Schneider J, Mall G, Turina M. Left ventricular myocardial structure in aortic valve disease before, intermediate, and late after aortic valve replacement. Circulation. 1989:79:744-55.

24. Ruel M, Kulik A, Rubens FD, Bedard P, Masters RG, Pipe AL, et al. Late incidence and determinants of reoperation in patients with prosthetic heart valves. Eur J Cardiothorac Surg. 2004;25: 364-70.

25. Morris JJ, Schaff HV, Mullany CJ, Morris PB, Frye RL, Orszulak TA. Gender differences in left ventricular functional response to aortic valve replacement. Circulation. 1994;90:II183-9.

26. Imanaka K, Kohmoto O, Nishimura S, Yokote Y, Kyo S. Impact of postoperative blood pressure control on regression of left ventricular mass following valve replacement for aortic stenosis. Eur J Cardiothorac Surg. 2005;27:994-9.

27. Rahimtoola SH. The problem of valve prosthesis-patient mismatch Circulation. 1978;58:20-4.

28. Vandervoort PM, Greenberg NL, Powell KA, Cosgrove DM, Thomas JD. Pressure recovery in bileaflet heart valve prostheses. Localized high velocities and gradients in central and side orifices with implications for Doppler-catheter gradient relation in aortic and mitral position. Circulation. 1995;92:3464-72.

29. Baumgartner H, Khan S, DeRobertis M, Czer L, Maurer G. Effect of prosthetic aortic valve design on the Doppler-catheter gradient correlation: an in vitro study of normal St. Jude, Medtronic-Hall, Starr-Edwards and Hancock valves. J Am Coll Cardiol. 1992;19: 324-32.

30. Henneke KH, Pongratz G, Bachmann K. Limitations of Doppler echocardiography in the assessment of prosthetic valve hemodynamics. J Heart Valve Dis. 1995;4:18-25. 